\title{
From Linguistic Research Findings to Useful Products for Australian Aboriginal Communities
}

\author{
Mary Laughren \\ School of Languages and Comparative Cultural Studies \\ The University of Queensland
}

\begin{abstract}
As a linguist investigating the Warlpiri language of central Australia since 1975 and the Waanyi language of the Gulf of Carpentaria region since 2000, my research has always had dual goals. One is to gain a better understanding of the nature of human language generally through detailed documentation and deep analysis of particular human languages, such as Warlpiri and Waanyi, and comparison with other languages; the other goal has been to produce materials of direct relevance and utility to the communities of these language speakers. This paper addresses the second goal. Firstly I briefly describe ways in which linguistic research findings have been 'converted' into pedagogic materials to support the bilingual education programs in the Warlpiri community schools (Lajamanu, Nyirrpi, Willowra and Yuendumu) from the mid 1970s to the present, a period which has seen dramatic technical innovations that we have been able to exploit to create a wide range of products accessible to the public which have their genesis in serious linguistic research. Secondly I discuss some aspects of the interdisciplinary (linguistics and anthropology) "Warlpiri Songlines" project (2005-9) for which over 100 hours of traditional Warlpiri songs were recorded and documented; older analogue recordings were digitised and ceremonial performances were video recorded. Thirdly, I touch upon the ongoing development of a Waanyi dictionary and language learning materials in collaboration with Waanyi people living at Doomadgee in north west Queensland who want to extend knowledge of their ancestral language within their community, since this language is no longer used as a primary language of communication. Finally, I cite some of the many recent innovative examples of ways in which linguists and anthropologists are drawing on contemporary technology to transmit their research findings to both the general public and to the communities in which their research is carried out.
\end{abstract}

$\mathrm{I}_{\mathrm{t}}^{\mathrm{n}}$ n 1973, the Australian Government (led by the Hon. Gough Whitlam of the Australian Labor Party) introduced the possibility for Aboriginal communities in the Northern Territory, then under direct federal jurisdiction, to choose to have their children educated in their traditional Aboriginal languages as well as English (see Hoogenraad, 2001). Several models of bilingual education were developed including the one adopted by the central Australian Yuendumu community in 1974 which involved initial literacy being taught in the Warlpiri language with a later transfer of literacy skills to English. As one of six linguists engaged by the Australian Department of Education (NT Division) as research officers to enable the implementation of bilingual education programs, I was responsible, in concert with Warlpiri and non-Warlpiri teaching staff and Warlpiri literacy workers for the implementation of the program first at Yuendumu and later extended to three other Warlpiri communities of Willowra, Lajamanu and Nyirrpi. 
Given that Warlpiri was the language which children were first being taught to read and write, and that there was no tradition of Warlpiri literacy, the primary imperative was to produce lots of reading materials suitable for young children being introduced to Warlpiri literacy and also to allow the ongoing development of their reading and writing skills and interest. Because the bilingual program was conceived as a bicultural program in which Warlpiri culture was to play a role in the children's education, as well as introducing them to the Australo-European culture of the wider Australia beyond their Warlpiri and central Australian horizons, my task was to work with Warlpiri adults to produce culturally, as well as pedagogically, suitable materials written in Warlpiri.

Community members enthusiastically contributed their knowledge, typically by recording traditional stories or information about the environment or other aspects of their Warlpiri world on reel-to-reel and cassette recorders. This oral material would be transcribed (pen on paper) by Warlpiri teaching assistants and literacy workers, literate in their language, employed by the NT Division of the Australian Education Department. The texts would be further edited in a collaboration between linguist and literacy worker or teaching assistant to create a suitable written text. This text would form the basis for a book or booklet or poster which would be illustrated by Warlpiri artists employed as literacy workers. These illustrations were mostly produced by the artists drawing with black ink. The text was painstakingly set using Letraset dry transfer strips of rub-on letters, applied one by one, in order to achieve the size and style of print required. The printing of multiple copies was done on roneograph machines before the purchase of a second hand offset printing press in 1976. Like the other field linguists working for the Department of Education in those early days of the NT bilingual programs, I contributed to most aspects of Warlpiri language materials production. ${ }^{1}$

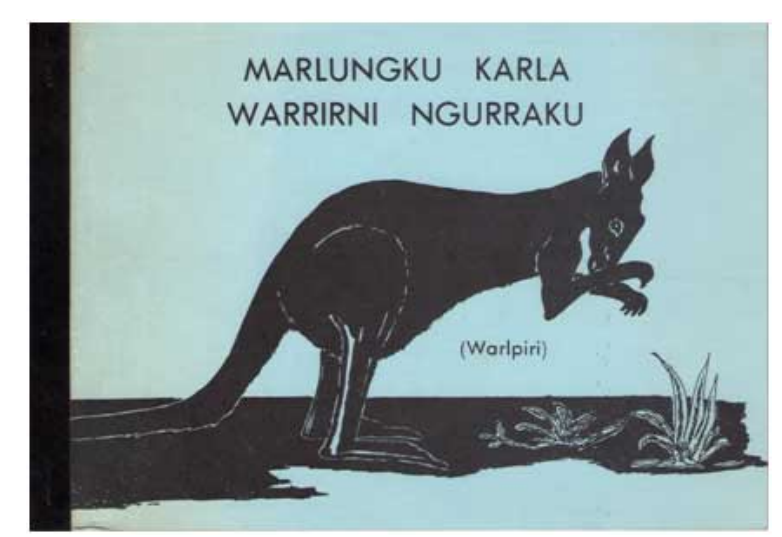

Cover of Warlpiri children's book produced at Yuendumu School 1975

Another aspect of my work was to provide linguistic resources that could be drawn on by teachers and teaching assistants to support their teaching, such as a dictionary of Warlpiri words, lists of words organized by semantic domain, ways of expressing mathematical concepts in Warlpiri, and ways in which Warlpiri classify the natural and social world. Again this was done by distilling linguistic information gained through collaboration with many Warlpiri speakers. Although there was a small core of young Warlpiri adults who had learned to read and write their language in the two years before I arrived in 1975, there was a need to extend this knowledge to other Warlpiri employed as teaching assistants or who aspired to work as literacy workers, so that teaching Warlpiri literacy classes for adults was also part of

\footnotetext{
${ }^{1}$ Books written in Aboriginal languages in the context of the NT bilingual education programs since 1973 are being digitized within the Living Archive of Aboriginal Languages (LAAL) Project discussed in Section 5.
} 
a linguist's job, as was teaching Warlpiri language to non-Warlpiri professionals working with Warlpiri people, mainly in Warlpiri communities. A tangible outcome of these Warlpiri language lessons was the production of a Learner's Guide to Warlpiri (book with accompanying cassette tapes) in collaboration with other linguists, and with Warlpiri speakers (Laughren, Hoogenraad, Hale \& Granites, 1996). ${ }^{2}$

In the mid-1980s, a technological revolution occurred that made local literature production easier, faster, better. This was the advent of portable computers, followed by the introduction of modern printers and the ability to link them. By the mid-1980s, Warlpiri bilingual programs were operating in Lajamanu and Willowra community schools in addition to Yuendumu, and in each centre local literature and pedagogic materials in Warlpiri were being produced. When Nyirrpi school was opened a decade later, the program was extended to the children in that community also. The 1990s saw the advent of digital audio and video allowing us to link recording devices to computers, edit sound, text, photographic and video files directly online and link all of these in new ways that could be exploited to produce more interesting and attractive pedagogic materials. In an on-line dictionary, text, sound and graphic objects (photographs, drawings, paintings, video films etc) can be linked and data can be quickly accessed via hyperlinks and search routines (see Thieberger, 2011).

SIL (Summer Institute of Linguistics) was one of the first linguistic research organisations to create computer programs (free shareware) specifically for the archiving, analysis and presentation of linguistic data in innovative online as well as traditional print formats. ${ }^{3}$ A Warlpiri Dictionary compiled by former SIL linguist Steve Swartz can be accessed online at http://ausil.org/Lexicons/Warlpiri/lexicon/index.htm. Another initiative drawing on new computer technology is the Kirrkirr application developed by Kevin Jansz, Christopher Manning and colleagues at Sydney University during the 1990s for the presentation of online dictionaries that link text, sound and graphic objects. ${ }^{4}$ Using this interface application, Warlpiri community members can readily access on their work, school or home computer the encyclopaedic Warlpiri dictionary I have compiled.

\footnotetext{
${ }^{2}$ The late Professor Ken Hale (Massachusetts Institute of Technology) who had researched Warlpiri (and other Australian languages) was sponsored by the Yuendumu Social Club to come to Australia in 1974 to conduct adult literacy classes in Warlpiri in Yuendumu that were attended by Warlpiri adults from several communities across central Australia. The writing system adopted had been created by Lothar Jagst, an SIL linguist based in Lajamanu.

${ }^{3}$ See <www.sil.org $>$.

${ }^{4}$ See $<$ www-nlp.stanford.edu/kirrkirr/>.
} 


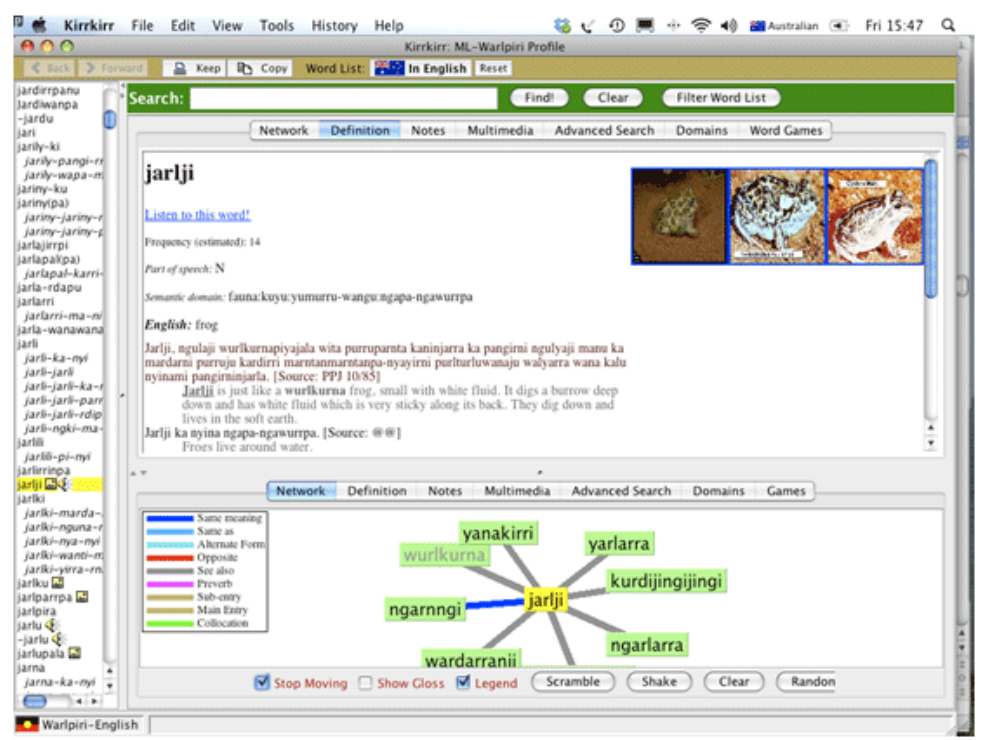

View of page of Warlpiri-English Dictionary using Kirrkirr interface application>

Dictionaries in traditional print form are still requested by communities as a written record of their language and also as a tool to be used in bilingual education programs. The Picture Dictionary Series published by IAD Press was expressly conceived to be used by Aboriginal children who are speakers of a central Australian language. A recent addition to this series is the Warlpiri Picture Dictionary I compiled with Robert Hoogenraad and over 100 Warlpiri speakers, drawing on the larger Warlpiri database. ${ }^{5}$

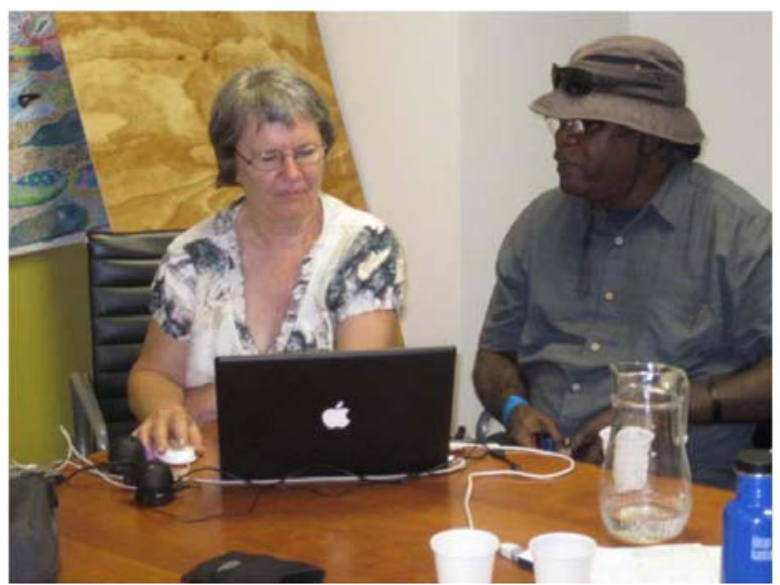

Mary Laughren and Steve Wanta Patrick Jampijinpa accessing Warlpiri documentation from Glowczewski collection in ODSAS database, Darwin 2011. (photo B. Glowczewski)

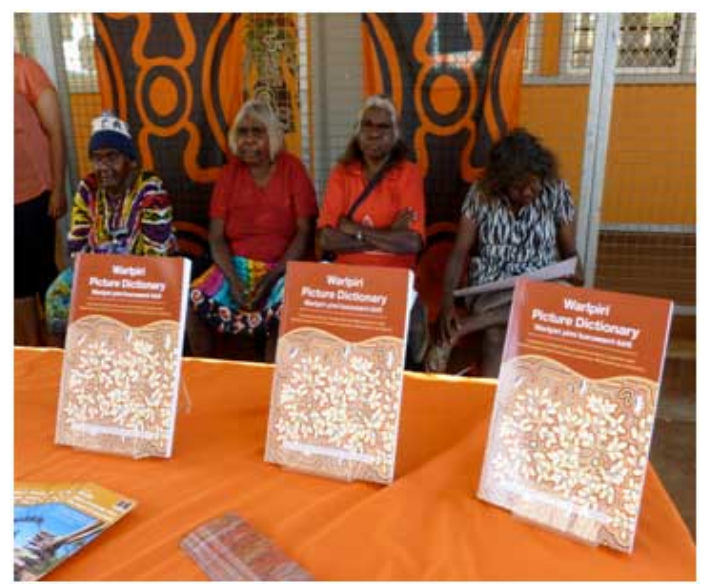

Warlpiri Picture Dictionary launch at Lajamanu 2012

\section{Warlpiri Songlines Project}

The aim of the "Warlpiri songlines: anthropological, linguistic and Indigenous perspectives" research project (funded by Australian Research Council Linkage grant LP0560567 with the Central Land Council and the Warlpiri Janganpa Association'6), carried out between 2005 and

\footnotetext{
${ }^{5}$ See $<$ https://iadpress.com/shop/warlpiri-picture-dictionary/>.

${ }^{6}$ Capitalised from revenues from gold mining in the Granites area of the NT, recognized as Warlpiri country under the Aboriginal Land Rights Act 1976.
} 
2009, was to record traditional ceremonial and ritual song repertoires sung by Warlpiri men and women. ${ }^{7}$

Audio recordings: Over 100 hours of audio recordings were made mostly by Georgia Curran in concert with Warlpiri people. These were transcribed and explicated by the late Jeannie Nungarrayi Egan (one of the teaching assistants who pioneered the Warlpiri bilingual program in Yuendumu school), her husband Tommy Jangala Rice and a group of Yuendumu elders who worked closely with Curran. ${ }^{8}$ As she made her recordings, Curran systematically archived the sound files with the Yuendumu based Pintubi-Anmatyerr-Warlpiri (PAW) media association $^{9}$ and distributed the recordings on CD to the singers and their families on request. Since completing her thesis on the songs relating to a particular initiation ritual (Curran 2010), all recordings have been archived at the Australian Institute for Aboriginal and Torres Strait Islander Studies (AIATSIS) in Canberra. Curran is now working on producing a series of illustrated books with accompanying sets of recordings on CD for publication by Batchelor Institute Press. Each book will document a particular song series. The documentation includes the Warlpiri song texts and English translation, other commentary and explanations provided by the singers, photographs of the singers and also body designs and paintings which relate to the same stories, country and people as the song series. This work will benefit younger Warlpiri people who are conscious with the passing of their elders of the loss of their cultural knowledge and traditions.

The Warlpiri Songlines project also included the digitisation of previously recorded oral materials including the extensive collection of Warlpiri oral texts and songs recorded in the mid 1980s mainly with Lajamanu Warlpiri by anthropologist Barbara Glowczewski (Director of Research at Centre National de Recherche Scientifique, Laboratoire d'Anthropologie Sociale, Collège de France, Paris). Glowczewski’s recordings and related field notes, transcriptions, commentaries, photographs and films are now part of the electronic archive "Online Digital Sources and Annotation System" (ODSAS) created by Laurent Dousset (Centre de Recherche et de Documentation sur l'Océanie, France). ${ }^{10}$ With access protocols in place, Warlpiri people can directly view and listen to this ODSAS-based records and may directly contribute to it, for example by annotating photographs or writing in the words of orals texts.

\footnotetext{
${ }^{7}$ A brief synopsis of this project can be found at http://info.anu.edu.au/ovc/media/media_releases/2007/August/150807_warlpiri_songlines, viewed 1 July, 2012.

${ }^{8}$ The chief investigators on this project were Prof. Nicolas Peterson (ANU), Dr. Mary Laughren (UQ), Dr.

Stephen Wild (ANU) and Ms Anna Meltzer (CLC). Curran's fieldwork was supported by a PhD stipend funded by the grant.

${ }_{9}^{9}$ See $<$ www.pawmedia.com.au $>$.

${ }^{10}$ See $<$ www.odsas.net $>$.
} 


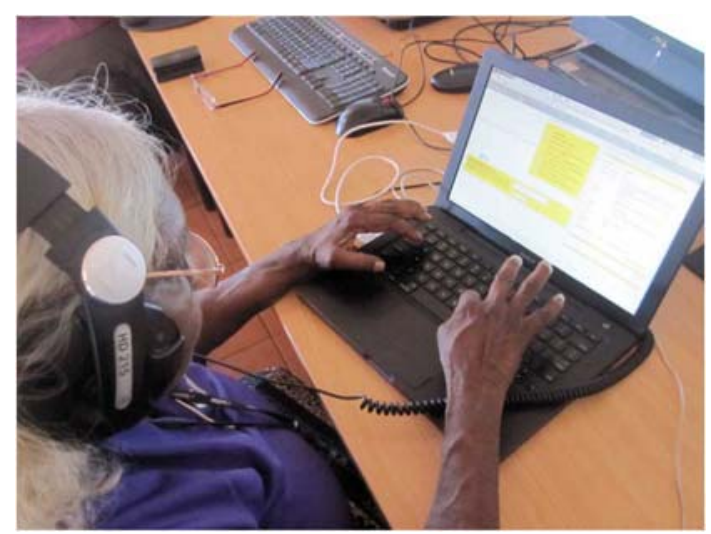

Elizabeth Ross Nungarrayi typing text of traditional story told by her father and recorded by B.

Glowczewski in 1984 archived on ODSAS (photo taken by B. Glowczewski Lajamanu 2011).

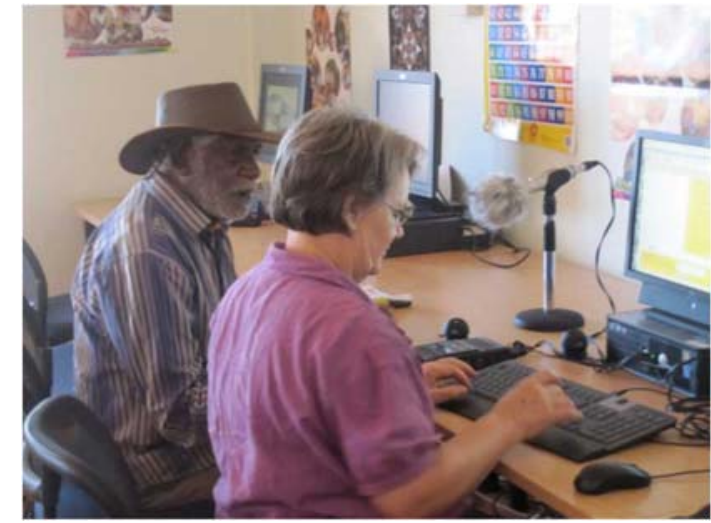

Jerry Patrick Jangala and Mary Laughren transcribing song text of purlapa performance recorded by B. Glowczewski at Lajamanu in 1984, archived on ODSAS. (Photo taken by B. Glowczewski at Lajamanu 2011.)

The audio recordings have also been locally archived in Warlpiri communities with the PAW media association and the Warnayaka Arts Centre (Lajamanu) and distributed to individuals on DVD and memory sticks.

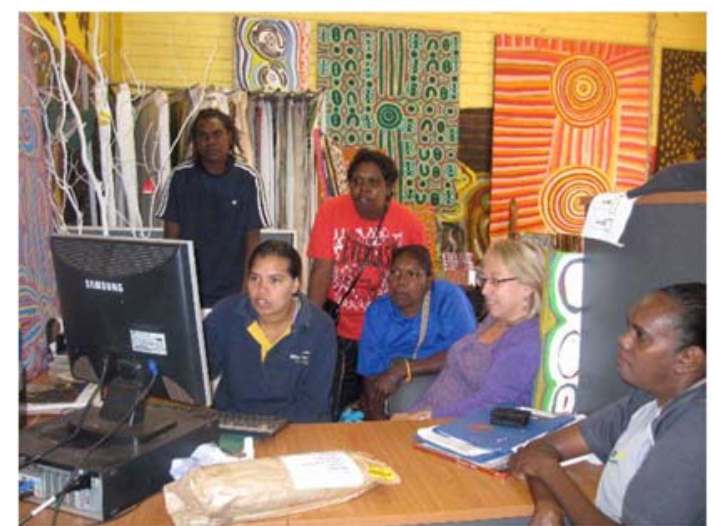

Warlpiri staff with Barbara Glowczewski at Warnayaka Arts Centre in Lajamanu, looking at Glowczewski's collection of Lajamanu Warlpiri documentation from 1980s. (photo taken by B. Glowczewski Lajamanu 2011)

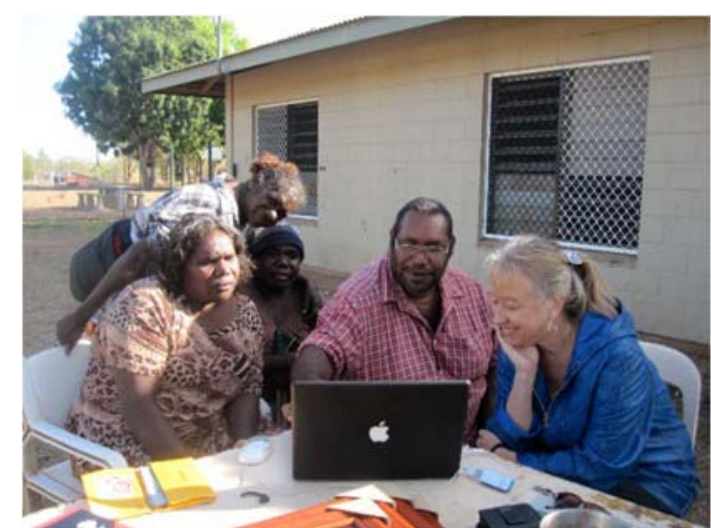

Family of Maureen Burns Nampijinpa view Barbara Glowczewski's collection of field notes, video and audio recordings and photographs archived on ODSAS. (photo taken by B. Glowczewski at Binjarri 2011)

Video recordings: Another output of the Warlpiri songlines project was the collaborative production of Yawulyu Wirliyajarrayi-wardingkiki: ngatijirri, ngapa (Willowra Songlines: budgerigar and rain), a Warlpiri language DVD made with senior Willowra women to record and transmit traditional song knowledge to younger Warlpiri. Although all generations of Warlpiri women and girls in communities such as Willowra, Yuendumu, Lajamanu and Nyirrpi continue their participation in community rituals, which involve painting the body (mainly the torso) and ceremonial objects with ancestral designs that relate to choreographed dance performances accompanied by traditional songs (all three elements are part of women's yawulyu artistic expression), few under the age of sixty years can sing the yawulyu verses 
which map relatively esoteric lyrics to a complex musical structure. ${ }^{11}$ In the Willowra Warlpiri community, the older women who have this knowledge are anxious to have their daughters and granddaughters learn to sing, as well as dance and paint the traditional designs and to understand their underlying meaning. So, a purely research and recording project centred around yawulyu performances by senior Willowra women attended by their younger relatives (including school-aged children), that were video and audio recorded by Myfany Turpin and Mary Laughren in 2009, was developed into a structured 55 minute film plus extra footage in which the women comment on the performances, explain the meaning of songs and take us to significant places in their country associated with the subjects of the performances and named in the songs. Additional filming was done in 2010 to incorporate these elements and the film was edited. ${ }^{12}$

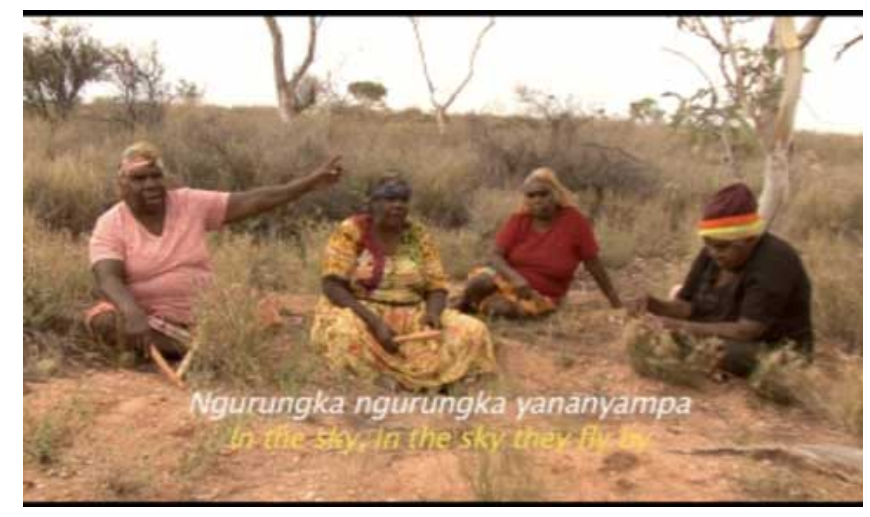

As most women under forty in the community, as well as some older women, have learned to read and write Warlpiri in the bilingual education program that has operated at Willowra school since the late 1970s, the words of the songs and the Warlpiri speech are written as subtitles as well as the English translation. Thus the new technologies allow the researcher, in collaboration with the community where the research is carried out and technical input from professional film-makers, to produce a 'pedagogic' tool that brings together all elements of ritual performance in a single object which allows instant access to sound, vision and text.

\section{Waanyi language recording initiative}

Between 2000 and 2005, I engaged on a project to document the Waanyi language traditionally spoken in the South Nicholson River area in the southern part of the Gulf of Carpentaria region straddling Queensland and the Northern Territory. My research concentrated on one elderly speaker who was very keen to have his language recorded: $\mathrm{Mr}$ Roy Seccin Kamarrangi who was in his eighties and was living in the Borroloola area (NT). ${ }^{13}$ I was able to make fifty-six hours of audio recordings and to take extensive field-notes with the aim of analysing the language to produce an academic dictionary and grammar, in collaboration with other linguists who recorded the language in the 1980s. ${ }^{14} \mathrm{Mr}$ Seccin belonged to the last generation of Waanyi people who grew up speaking Waanyi as their first language; while later generations identify as Waanyi and use Waanyi words in their English and/or Kriol speech, they no longer control Waanyi grammar and do not create Waanyi sentences.

\footnotetext{
${ }^{11}$ This is documented in some detail in Barwick, Turpin and Laughren (2011).

12 The additional footage was shot by filmmaker Wiriya Sati who also led the editing team.

${ }^{13} \mathrm{Mr}$ Seccin passed away in Borroloola NT in 2006.

${ }^{14}$ These collaborating researchers are linguists Gavan Breen and Luise Hercus and anthropologist John Dymock.
} 
In 2007, I was approached by a Waanyi community organisation with roots in Doomadgee (Qld) to continue recording Waanyi with two other speakers with the aim of eventually producing a dictionary and other materials that would not only serve as a record of the language but also as a means of reviving the language and extending knowledge of it among young Waanyi people. ${ }^{15}$ I have used the SIL database application Toolbox to organize the language data, which is displayed in electronic form using the Kirrkirr application. This allows photographs and original sound files to be linked to the text (e.g., head words, example sentences) and enables a range of advanced searches along with innovative ways of displaying related words (synonyms, words with similar meaning). The application also has an interactive function which generates a number of word games, allowing a user to both extend and test their Waanyi language knowledge, as well as a 'notes' function that enables users to add their own text.

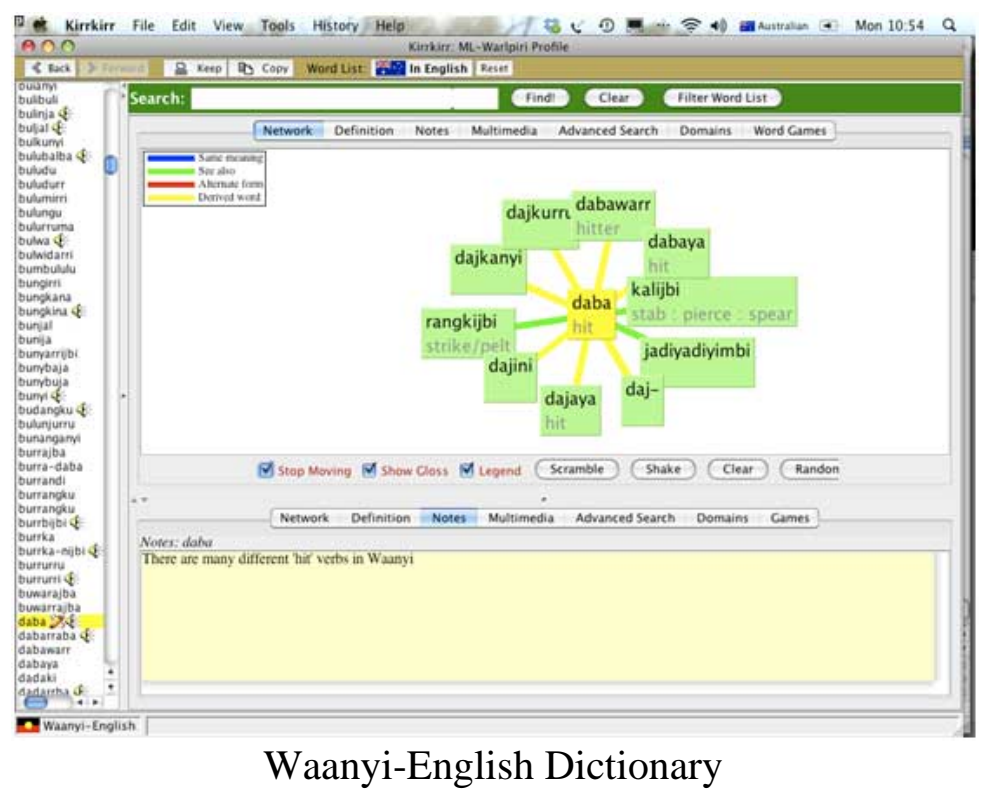

A traditional print version of the Waanyi dictionary for use in the Waanyi community has been derived using SIL's Lexique Pro application. Another of the advantages of the electronic dictionary display using applications such as Kirrkirr is that the user has a large degree of control over the amount and sort of information they access, which makes it highly adaptive to a range of users with different needs and motivation.

\section{More novel ways of transmitting linguistic research findings}

Linguists in Australia, and elsewhere, are very conscious of the need and desirability to transmit their research findings to a wider public. Those working on endangered languages such as Australian Aboriginal languages have been particularly concerned that their research goals and findings be understood by the language speakers with whom they work and further that this work contribute positively to the life of the language speakers and their families. Many linguists have (and are) engaged in the types of projects I have described in the preceding sections. Before concluding, I would like to mention some further instances where

\footnotetext{
${ }^{15}$ Reviving the Waanyi language is one of the community projects of Northern Project Contracting (see www.northernprojectcontracting.com.au/Our-Community/Community-Projects.aspx).
} 
linguists have made use of modern internet technology to communicate directly to communities and a wider public the aims, methods and results of their research.

Online archives. The first initiative is that of online archives where language data and a range of language resources and information about languages is made publicly available. I have already mentioned the ODSAS initiative for the archiving of mainly ethnological data, and the SIL website which hosts Ethnologue, a database of information about the world's languages.

An Australia-based online archive is the Pacific and Regional Archive for Digital Sources in Endangered Cultures (PARADISEC) hosted at the University of Sydney. ${ }^{16}$ Another Australia- based website which gives public access to information about Australian languages is the AUSTLANG (Online Australian Indigenous Languages database) hosted at the Australian Institute for Aboriginal and Torres Strait Islander Studies in Canberra. ${ }^{17}$ Another Australia based archive currently under construction is the Living Archive of Aboriginal Languages (LAAL), hosted by Charles Darwin University, which aims to digitize and thus preserve all the extant books and other pedagogic materials produced in the context of the NT Bilingual Education Program. This archive is designed to be interactive so that community members and others will be able to access it and to continue to add value, for example by adding oral recordings or readings of the materials or other relevant information about the authors and illustrators, the content and the production context. ${ }^{18}$

Moving beyond Australia, the Hans Rausing Endangered Languages Project at the School of Oriental and African Languages (SOAS), London (http://www.hrelp.org) makes available via its web presence a large body of work on the endangered languages that it has funded, including on Australian languages; both technical and non-technical information can be accessed from this site. ${ }^{19}$ Yet another example of international collaboration is the Endangered Languages Project, an online resource to record, access, and share samples of research on endangered languages, as well as to share advice and best practices for those working to document or strengthen languages under threat. ${ }^{20}$ A similar online presence is Sorosoro which provides information readily accessible to a wide audience about the world's endangered languages and the ongoing situation of language loss. ${ }^{21}$ These sites and many other similar ones can be accessed via links from the Linguist List site. ${ }^{22}$ The Open Language Archives Community (OLAC) site also draws together language data from online language archives based around the world. ${ }^{23}$

Research Project websites: A number of linguistic research projects have dedicated websites where the project is presented to the public in a clear attractive manner. An excellent example of such a site in the Australian context is the Aboriginal Child Language Acquisition Project led by Professor Gillian Wigglesworth (U. Melbourne). ${ }^{24}$

Online blogs and podcasts. Many of the websites created by linguists host blogs where linguists aim to engage with colleagues and a wider public on a range of issues relating to

\footnotetext{
${ }^{16}$ See $<$ http://www.paradisec.org.au $>$.

${ }^{17}$ See <http://www.aiatsis.gov.au/research/projects/austlang.html $>$.

${ }^{18}$ See $<$ http://www.cdu.edu.au/centres/laal/>.

${ }^{19}$ See $<$ http://www.cdu.edu.au/centres/laal/>.

${ }^{20}$ See $<$ http://www.endangeredlanguages.com/>.

${ }^{21}$ See $<$ http://www.sorosoro.org $>$.

${ }^{22}$ See $<$ www.linguistlist.org $>$.

${ }^{23}$ See $<$ http://www.language-archives.org $>$.

${ }^{24}$ See <http://linguistics.unimelb.edu.au/research/projects/ACLA/index.html>.
} 
language, from technical linguistic issues to language politics. The linguistic topics are written about in a clear non-technical manner. Some good examples of these are the PARADISEC based blog moderated by Professor Jane Simpson (ANU) at http://www.paradisec.org.au/blog and Professor Claire Bowern's (Yale) blog at http://anggarrgoon.wordpress.com. ${ }^{25}$ The Hans Rausing Endangered Languages Project website also posts podcasts to communicate the research activities they sponsor. YouTube posts. Drawing on the ever-wider access to the internet in Australian Aboriginal communities, although such access is still largely limited to institutions there and only rarely found in private houses, linguists have posted on YouTube reports on their research findings specifically addressed to the members of the communities in which their research was carried out. These reports are spoken in clear English with supporting graphics and linked speech to illustrate the types of data found and the conclusions drawn. Such postings are immediately accessible to the targeted audience in a way that a conventional written report is not. An excellent example is provided by Carmel O'Shannessy (U. Michigan) reporting on her research into the language used by children in some Warlpiri communities. ${ }^{26}$

\section{Concluding Remarks}

My aim here was to present some examples of how linguistic research findings are being communicated to a wider public, with particular emphasis on research being done on Australian Aboriginal languages and the communication of the data and the analytic findings to the Aboriginal people in the communities where the research is carried out. I also gave some examples of how linguistic research can provide the basis for useful products such as pedagogical materials and reference works. This was illustrated by some examples with which I was involved and in giving these I have tried to reflect how the changes in technology since the mid-1970s have revolutionized not only our research techniques but the possible ways in which linguistic research data can be manipulated, displayed and communicated. These technologies have opened up so many more means by which a linguist can communicate their research findings to an increasingly diverse audience. Finally, I gave some examples of how linguists, especially those working on minority and often highly endangered languages, have embraced the new digital technology and the internet-based possibilities to share their research findings.

\footnotetext{
${ }^{25}$ The PARADISEC hosted blog "Endangered Language and Cultures" is described on the site as "a multiauthored blog about linguistics, language documentation, research technology, and generally everything to do with endangered languages and cultures. It is predominantly written by linguists Jane Simpson and Peter Austin, archivists from PARADISEC, and guest contributors".

${ }^{26}$ See <http://www.youtube.com/watch?v=VLWYTZ8RP-I>.
} 


\section{WORKS CITED}

Barwick, Linda, Turpin, Myfany and Laughren, Mary. (2011). Sustaining women’s Yawulyu/Awelye: some practitioners' and learners' perspectives. Paper presented at Sustainability and Ethnomusicology symposium, Queensland Conservatorium Griffith University, March. [To appear in Special Issue of Musicology Australia, guest-edited by Katelyn Barney and Dan Bendrups]

Curran, Georgia. (2010). Contemporary Ritual Practice in an Aboriginal Settlement: The Warlpiri Kurdiji Ceremony. PhD Dissertation, ANU.

Hoogenraad, Robert, Laughren, Mary et al. (2012). Warlpiri Picture Dictionary: Warlpiri Yimi Kuruwarri-kirli. Alice Springs: IAD Press.

Hoogenraad, Robert. (2001). Critical reflections on the history of bilingual education in Central Australia. In Simpson, J., Nash, D., Laughren, M., Austin, P. \& Alpher, B. Forty Years On: Ken Hale and Australian Languages, 123-150. Canberra: Pacific Linguistics 512.

Laughren, Mary, Hoogenraad, Robert, Hale, Ken \& Granites, Robin Japanangka. (1996). A Learner's Guide to Warlpiri, Tape course for beginners, Wangkamirlipa Warlpiri. Alice Springs: IAD Press.

Laughren, Mary, Turpin, Myfany and Morton, Helen Napurrurla. (2010). Yawulyu Wirliyajarrayi-wardingkiki: ngatijirri, ngapa. Willowra songlines: Budgerigar and rain. DVD 55 minutes, plus extras. Willowra, NT, Australia, Willowra Community.

Thieberger, Nicholas. (2011). Building a lexical database with multiple outputs: examples from legacy data and from multimodal fieldwork. International Journal of Lexicography, 24(3) 463-472. 